\title{
Juan Carlos Onetti: una vida literaria ${ }^{1}$
}

\author{
Raquel García
}

\section{Uno}

Juan Carlos Onetti supo desde la adolescencia -cursó sólo hasta primer año de estudios secundarios- que quería ser escritor. Varias veces dijo concebir la escritura como un acto de amor, jamás como un trabajo u obligación. Nació en Uruguay, hijo de la extendida pequeña burguesía de aquel país todavía bucólico, estatista, paternalmente generoso. Fue auténtico en lo que escribió y vivió forjando para sí una ética propia, ajena por igual a la de la pequeña burguesía de la que provenía, y a la preponderante entre los intelectuales de su medio.

Escéptico, como su personaje de tantas narraciones -el doctor Díaz Grey-, Onetti fue conciencia lúcida de los hechos de su tiempo. Pasó su vida adulta trabajando a disgusto en diversos oficios, principalmente en los de publicista, periodista y -ausente- director de

1 La base de este texto es la ponencia pronunciada en el Ciclo de Conferencias de Literatura Latinoamericana organizado por el Instituto Nacional de Cultura del Perú, en el Museo de la Nación, en Lima, octubre de 1999. 
bibliotecas públicas municipales de Montevideo. Habitó no sólo en esa ciudad, sino también por largos y discontinuos períodos, en la cosmopolita Buenos Aires. Fue un escritor privado y un intelectual riguroso: Entre 1939 y 1941 fue secretario de redacción del recién fundado y pronto muy prestigioso semanario Marcha de Montevideo. No integró grupo literario ni partido político alguno, aunque toda su vida fue un hombre de izquierda. Siguiendo probablemente el consejo de Rainer María Rilke a un joven poeta, Onetti se volvió sobre sí mismo para examinar si moriría, de serle negada la escritura; descubrió que no podía vivir sin escribir, por tanto fue escritor en cada acto de su vida. Buscó dentro de sí, aprendiendo de los maestros, pero sin imitar a nadie. Afirmó que esta actitud era la única correcta en un escritor. Así es que bajo el seudónimo de Periquito el aguador, en 1939 escribió en el semanario Marcha la siguiente opinión sobre por qué se escribe, cuál es la tarea del escritor, y sobre la literatura de pretensiones declaradamente políticas, tan practicada por entonces:

Cuando un escritor es algo más que un aficionado, cuando pide a la literatura algo más que los elogios de honrados ciudadanos que son sus amigos, o de burgueses con mentalidad burguesa que lo son del Arte, con mayúsculas, podrá verse obligado por la vida a hacer cualquier clase de cosa, pero seguirá escribiendo. No porque tenga un deber a cumplir consigo mismo, ni una urgente defensa cultural que hacer, ni un premio ministerial para cobrar. Escribirá porque sí, porque no tendrá más remedio que hacerlo, porque es su vicio, su pasión y su desgracia.

Y si, llevado a un terreno de actividad política, deja de hacer literatura para dedicarse a redactar folletos de propaganda, que nadie se haga cruces en homenaje a su inexistente sacrificio. El escritor no era escritor, sino político; terminó por encontrarse a sí mismo. Hay numerosos casos de vocaciones tardíamente despiertas que podrían citarse ${ }^{2}$.

A Onetti le creció el aura de artista solitario y tímido en las dos ciudades capitales del Río de la Plata, una hombría taciturna sin alardes, conocida su debilidad por la noche, las prostitutas y las niñas-adolescentes. En muchas de sus narraciones el desvelo del deseo proviene de una niña, aún no contaminada, no degradada a mujer:

2 Marcha. Montevideo, 27 de octubre de 1939. 
(Elvirita) ... Yo mirándole las piernas tan largas, que empiezan en unos calzados absurdos que se llaman botinas, todavía blancas porque el verano aún no llega. Y miro con disimulo las botinas donde las piernas nacen y van creciendo hasta unirse con esa fuente de mi pena de hoy, mi leve desespero ${ }^{3}$.

Amó a muchas mujeres y cuatro veces se casó, y sus dos primeras esposas fueron primas suyas, hermanas entre sí.

Por décadas no fue muy conocido ni, menos aún, leído, más allá de algunos círculos intelectuales locales. En los efervescentes, arrolladores años sesenta, sus libros comenzaron a circular como rara exquisitez entre algunos entendidos, aquéllos, pocos, iniciados en el rito de leerlo. El autor nunca se preocupó por imponerse públicamente, jamás promocionó sus libros. En cada concurso literario al que se presentó, su obra obtenía, cuanto mucho, un segundo o tercer lugar. Al igual que otro narrador uruguayo algo anterior a él (Felisberto Hernández, m. 1964), cultivador del relato "fantástico", Onetti escribió sus primeros libros desde la soledad más absoluta, ignorado por la crítica.

El crítico literario Ángel Rama reeditó en su legendaria editorial Arca, de Montevideo, en 1965 su primera, breve novela, El pozo (1939), y le dedicó un ensayo consagratorio: Origen de un novelista y de una generación literaria (la llamada "Generación de la Crisis", o "de Marcha"). Más tarde se revelaría su importancia como pionero en el uso de recursos y técnicas narrativas inéditas en español: El discurso fragmentado y ambiguo, la elipsis y la ironía, los saltos abruptos en el tiempo y en el punto de vista, los múltiples narradores, la ficción dentro de la ficción, la autorreferencialidad del discurso narrativo y sus relaciones intertextuales explícitas son incorporados tempranamente por Onetti a la narrativa de la lengua española, a partir de sus lecturas de Marcel Proust, James Joyce, William Faulkner. Su lenguaje, en apariencia poco cuidado, es el de los desarraigados habitantes de la ciudad moderna, el que había sido integrado a la literatura rioplatense en las intensas narraciones del argentino Roberto Arlt (m. 1942).

En el caso de Onetti, el concepto de "generación" aclara poco o nada, porque su visión del mundo y su lenguaje fueron precoces en

3 Onetti, J.C. Cuando ya no importe (1993). Buenos Aires: Alfaguara, 1993, p. 167. 
la literatura de nuestro continente; muy poco tienen que ver con el de la enorme mayoría de sus contemporáneos de lengua española. Así, por ejemplo, el narrador peruano Ciro Alegría nació el mismo año que Onetti. Alegría es el último de los grandes novelistas de lo rural y lo regional americano, y su monumental novela El mundo es ancho y ajeno de 1941 representa ejemplarmente la narración de los años veinte, treinta y hasta cuarenta. Ese discurso era el que esperaban y celebraban los narradores de América Latina por esos años. Por ello, en 1941, el certamen internacional de la editorial Farrar y Reinhart de Nueva York sólo premió la novela de Alegría, mientras Tiempo de abrazar de Onetti pasaba desapercibida (el manuscrito se perdió luego, y se publicaría recién en 1974 en Buenos Aires).

Sin embargo, Onetti fue reconocido como maestro y guía por los autores del llamado "boom" de la novela hispanoamericana. Al igual que Juan Rulfo y Miguel Ángel Asturias, Onetti abrió nuevos caminos por los que, años más tarde, se adentrarían con maestría y autoconfianza los autores de la llamada nueva novela hispanoamericana (C. Fuentes, 1969), la que por fin haría que las literaturas de nuestro continente ingresaran al canon de lo que los lectores del hemisferio Norte consideran literatura universal.

Así, en 1967, el joven narrador Mario Vargas Llosa, al recibir en Caracas el premio Rómulo Gallegos por su también monumental novela La casa verde, manifestó la deuda de su generación con el poco conocido Onetti: “... otros escritores latinoamericanos, con más obra y más méritos que yo, hubieron debido recibir (este premio, RG) en mi lugar - pienso en el gran Onetti, por ejemplo, a quien América Latina no ha dado aún el reconocimiento que merece-..." ${ }^{\prime 4}$. Onetti se hace más conocido dentro y fuera del Río de la Plata en 1974, pero por motivos no literarios: Los militares, que ya entonces detentaban el poder político en el Uruguay, lo encarcelaron, acusándolo de inmoral y pornográfico, como también encarcelaron a los otros tres miembros del jurado literario que había concedido el premio de la categoría "cuentos" del certamen de Marcha a una narración ("El

4 Vargas Llosa, M. "La literatura es fuego" (1967). Antología mínima. Buenos Aires: Editorial Tiempo Contemporáneo, 1969, p. 156. 
guardaespaldas", de Nelson Marra) en que se aludía muy directamente a un personaje poco decoroso de la vida nacional. Después de unos meses internado en el Hospital Militar, y habiéndose afianzado entre tanto el régimen (la dictadura militar se mantendría hasta 1985), Onetti aceptó una invitación para viajar a España en calidad de escritor. En Madrid se quedaría a vivir sus últimos 20 años. Allí el autor conoció lo que puede llamarse el éxito, que para él no dejó de ser una serie de malentendidos: En España, gracias a la eficiente gestión de su agente literaria Carmen Balcells, se reeditaron sus obras -novelas y cuentos dispersos, aparecidos inicialmente en ediciones pequeñas o inaccesibles fuera del Río de la Plata- y se multiplicaron las traducciones a muchas lenguas. En abril de 1981 recibió de manos del rey Juan Carlos el codiciado premio Cervantes. Asistido por la última de sus esposas, la violinista Dorothea Muhr ("Dolly"), Onetti pasó todos esos años leyendo, escribiendo, bebiendo y fumando en la cama, recluido en su departamento de la avenida de América, rodeado de libros y periódicos, aparentemente indiferente al mundo exterior, escéptico ante la historia, como son todos los personajes de sus cuentos y novelas.

\section{Dos}

Es forzoso reconocer que la trayectoria vital de Onetti es una suerte de alegoría de su literatura. Y esa literatura puede considerarse una apología del fracaso. Sus personajes, como el autor, conocen de la abyección humana y saben que el tiempo jamás ennoblece, sólo corrompe (es el tema de todos sus textos, pero no puedo dejar de mencionar el intenso, demoledor cuento "Bienvenido, Bob"). Onetti comunicó la visión del mundo que parte del Eclesiastés y puede reconocerse en moralistas como Séneca, Montaigne, los existencialistas. Sus inclementes hallazgos sobre la vida, la inutilidad de todo esfuerzo, los transmite Brausen, el protagonista de La vida breve, cuando piensa: “Toda la ciencia de vivir está en la sencilla blandura de acomodarse en los huecos de los sucesos que no hemos provocado con nuestra voluntad, en no forzar nada, ser, simplemente, cada minuto" ${ }^{5}$.

5 Onetti, J.C. La vida breve (1950). Barcelona: Argos-Vergara, 1979, p. 233. 
Los esfuerzos no se compensan jamás porque el envejecimiento no se detiene, los momentos libres de mezquindades escasean, la comunicación no se da, todas las relaciones humanas se revelan finalmente como gratuitas fugas de lo único constante: la soledad y la declinación. Propio también de muchos personajes onettianos en un momento de lucidez es el siguiente hallazgo de Larsen:

Sospechó, de golpe, lo que todos llegan a comprender, más tarde o más temprano: que era el único hombre vivo en un mundo ocupado por fantasmas, que la comunicación era imposible y ni siquiera deseable, que tanto daba la lástima como el odio, que un tolerante hastío, una participación dividida entre el respeto y la sensualidad eran lo único que podía ser exigido y convenía dar6.

El que escribe está inconfundiblemente presente en cada uno de sus textos: Sus personajes suelen ser su alter ego, y en todos los casos son sus prójimos más cercanos. Onetti conversó y convivió con sus personajes por sesenta años, también en los veinte años del exilio en Madrid.

Eladio Linacero es probablemente el primero de una serie de "héroes" onettianos, los indiferentes morales importados de la cultura europea de entreguerras, agobiados por el tedio, hastiados de la realidad mezquina, trivial y sucia. Más que cualquier otra cosa, los seres humanos están solos: “... toda la noche está, inapresable, tensa, alargando su alma fina y misteriosa en el chorro de la canilla mal cerrada, en la pileta de portland del patio. Ésta es la noche. Yo soy un hombre solitario que fuma en un sitio cualquiera de la ciudad...7. Esos seres ensimismados huyen a través del sueño: "Yo soy un pobre hombre que se vuelve por las noches hacia la sombra de la pared para pensar cosas disparatadas y fantásticas" ${ }^{\prime \prime}$, afirma Linacero en la breve novela El pozo de 1939. La nouvelle son las confesiones de este hombre pequeño y misántropo, escritas en su miserable, compartido, cuarto de alquiler en Montevideo, la víspera del día en que cumple los 40 años. Todas las narraciones del autor transcurren en espacios cerrados:

Hace un rato me estaba paseando por el cuarto y se me ocurrió de golpe que lo veía por primera vez. Hay dos catres, sillas despatarradas

6 Onetti, J.C. El astillero (1961). Bogotá: Oveja Negra, 1984, p. 299.

7 Onetti, J.C. El pozo (1939). Montevideo: Arca, 1967, p. 45.

8 Ibídem, p. 44. 
y sin asiento, diarios tostados de sol, viejos de meses, clavados en la ventana en el lugar de los vidrios.

Me paseaba con medio cuerpo desnudo, aburrido de estar tirado, desde mediodía, soplando el maldito calor que junta el techo y que ahora, siempre, en las tardes, derrama adentro de la pieza. Caminaba con las manos atrás, oyendo golpear las zapatillas en las baldosas, oliéndome alternativamente cada una de las axilas. Movía la cabeza de un lado a otro, aspirando, y esto me hacía crecer, yo lo sentía, una mueca de asco en la cara. La barbilla, sin afeitar, me rozaba los hombros ${ }^{9}$.

Esa mueca de asco atañe no sólo al mal olor del propio cuerpo, también a la percepción de todo cuanto lo rodea, la constatación de que todo lo que creyó bello está perdido. Cuando joven, Linacero había sido breve y milagrosamente visitado por un sentimiento maravilloso: el amor, que compartió con una muchacha, Ceci. "... tenía trajes con flores de primavera, unos guantes diminutos y usaba pañuelos de tela transparentes que llevaban dibujos de niños bordados en las esquinas $^{\prime 10}$. Pero pasados unos años de matrimonio, la muchacha inadvertidamente se ha transformado en Cecilia, una mujer, por tanto alguien con quien por definición ya no pueden soñarse locuras. La mujer es un ser que "puede distinguir los diversos tipos de carne de vaca y discutir seriamente con el carnicero cuando la engaña"11. Una marcada misoginia sobrevuela gran parte de la narrativa de Onetti y será atemperada recién en sus últimas novelas: “Terminan siendo todas iguales, con un sentido práctico hediondo, con sus necesidades materiales y un deseo ciego y oscuro de parir un hijo"12. A Linacero no le queda otra salida, para sobrevivir, que soñarse otras vidas: Se imagina entre la nieve: leñador en Alaska, minero en Canadá o escritor de una gran obra en los Alpes suizos; en cada caso el "sueño de la cabaña de troncos" sublima, corrige, una experiencia abyecta, la realidad triste por mediocre, en este caso la vejación que el mismo Linacero, adolescente, había infligido gratuitamente, sin deseo, a la joven Ana María, la que murió poco después y desde entonces lo visita en sueños. En

9 Op. cit., p. 8

10 Op. cit., p. 28.

11 Ibídem.

12 Ibídem. 
sueños puede comunicarse sin humillación ni temor con la prostituta Ester, y con el poeta Cordes. Después de los sueños, es la escritura el otro camino que se revela hacia esa, otra realidad:

... ahora se me importa poco de todo, de la mugre y el calor y los infelices del patio. Es cierto que no sé escribir, pero escribo de mí mismo ${ }^{13}$.

Y más adelante:

... ahora quiero hacer algo distinto. Algo mejor que la historia de las cosas que me sucedieron. Me gustaría escribir la historia de un alma, de ella sola, sin los sucesos en que tuvo que mezclarse, queriendo o no $^{14}$.

\section{Tres}

Por lo menos a partir de La vida breve (1950) todas las narraciones de Onetti remiten a un estado de ánimo cambiante pero siempre el mismo, inconfundible como su estilo moroso, empantanante, siempre en peligro de naufragar, y sin embargo siempre triunfante, imprescindible. Sus personajes y el paisaje en que ellos se mueven, los hombres y mujeres desencantados, aparentemente distraídos que pueblan las narraciones de Onetti, recrean una ciudad provinciana recostada en un río de aguas calmas y turbias, que suele llamarse Santa María, aunque igualmente puede ser la también inventada Lavanda, o las extraliterarias Montevideo, o Buenos Aires. Los sanmarianos también se instalan, de tan conocidos, en la vida de los lectores, se convierten en los prójimos reales de todos los que consienten en regresar al espacio dolorosamente humano que fluye de la prosa de Onetti. Cada narración suya es un capítulo de otro libro mayor. Desde cada novela y cuento el lector aprende a reconocer los puentes tendidos hacia todo el resto, y la multitud de personajes y de situaciones se constituyen en obra enciclopédica, al modo de la narrativa de Balzac, Galdós, Proust o Faulkner. Sus 15 novelas y 40 cuentos constituyen, como en los mencionados autores, un cosmos autosuficiente, situado preferentemente en un espacio de ruina y catástrofes humanas, la ciudad de Santa María.

13 Op. cit., p. 8.

14 Op. cit., p. 9. 
La novela La vida breve es un punto de inflexión decisivo en la narrativa de Onetti e incluso en la narrativa de América Latina de este siglo. Allí también hay un protagonista, Juan María Brausen, desesperado por el tedio y la falta de sentido de la existencia:

A esta edad es cuando la vida empieza a ser una sonrisa torcida ... y se descubre que (la vida) está hecha, desde muchos años atrás, de malentendidos. Gertrudis, mi trabajo, mi amistad con Stein, la sensación que tengo de mí mismo, malentendidos. Fuera de esto, nada; de vez en cuando, algunas oportunidades de olvido, algunos placeres, que llegan y pasan envenenados. Tal vez todo tipo de existencia que pueda imaginarme debe llegar a transformarse en un malentendido. Tal vez, poco importa. Entre tanto, soy este hombre pequeño y tímido, incambiable, casado con la única mujer que seduje o me sedujo a mí, incapaz, no ya de ser otro, sino de la misma voluntad de ser otro ${ }^{15}$.

La fuga de Brausen de esta realidad sin deseo se consuma por dos vías paralelas: Un primer alter ego se forja con asombrosa facilidad en su vida cotidiana misma. Desde su diminuto apartamento en Buenos Aires, en el que su esposa Gertrudis lo ha abandonado, Brausen ausculta las conversaciones que tienen lugar en el apartamento vecino. Allí se ha mudado recientemente una mujer pequeña y vulgar cuya voz y presencia lo fascinan: la prostituta Queca. El aire de ese apartamento, al que puede ingresar fortuita, subrepticiamente una primera vez, le descubre como ráfaga la posibilidad de una vida breve:

Empecé a moverme sobre el piso encerado, sin ruido ni inquietud, sintiendo el contacto con una pequeña alegría a cada lento paso. Calmándome y excitándome cada vez que mis pies tocaban el suelo, creyendo avanzar en el clima de una vida breve en la que el tiempo no podía bastar para comprometerme, arrepentirme o envejecer ${ }^{16}$.

Brausen adoptará otra identidad y será Arce para frecuentar a la Queca, a quien poco después, como revelación de la propia siempre buscada identidad, se dispone a asesinar en una operación necesaria de limpieza.

15 Onetti, J.C. La vida breve (1950). Barcelona: Argos-Vergara, 1979, pp. 50- 51.

16 Op. cit., p. 53. 
El otro alter ego de Brausen surge a través de la escritura, mientras se esfuerza por redactar el guión para una película que le ha encomendado su amigo Stein, en la agencia de publicidad en la que ambos trabajan. Brausen imagina con atención y cuidado crecientes al doctor Díaz Grey, médico en Santa María, quien observa la plaza y el río desde la ventana de su consultorio bajo el sol del mediodía aletargado, hasta que recibe la puntual visita de Elena Sala, mujer bella y misteriosa a la que debe inyectar morfina.

Pero Arce no podrá asesinar a la Queca, porque se le ha adelantado Ernesto, el antiguo cafisho de la mujer; entonces Arce/Brausen asume el asesinato ejecutado por el joven Ernesto, el que él mismo hubiese querido realizar, y huye con él de la policía bonaerense, para después de accidentados traslados en trenes y taxis arribar a Santa María. La ficción dentro de la ficción termina por borrar todos los bordes convencionales del pacto entre lector y texto: El doctor Díaz Grey, tras el suicidio de Elena Sala, sigue compulsivamente a Lagos, el viudo de Elena, y a Oscar Owen, el Inglés, el bello antiguo amante de Elena y de su marido, y a una joven violinista que se les suma y es, de alguna manera, también Gertrudis y Elena Sala y hasta la Queca. Todos ellos están disfrazados en tres días de festejos de carnaval en Santa María, y se han dado, tras robar morfina y asesinar sin meditación a un hombre, también a la fuga de las autoridades. En esta segunda parte de La vida breve ya no es Brausen la única voz narradora, también el doctor Díaz Grey narra por momentos. Los personajes se independizan de su creador. El creador primero, Onetti, cuyo nombre lleva también un personaje, se ha duplicado en el creador Brausen, y éste en Díaz Grey, como en un juego de espejos. Así Brausen/Arce, recién arribado a Santa María, se sabe sin admitirlo autor de un deicidio, cuando escribe:

Junto a la ciudad y fuera de ella me era posible estirar las piernas bajo la mesa de la fonda, hojear números viejos de "El Liberal" de Santa María, destacar a Ernesto como hacia una fecha futura de la que habría de traerme, sin saberlo, adheridas a su gesto y a su voz como modalidades, respuestas a mi curiosidad, anticipaciones que se harían obvias un momento después de conocidas. Me era posible examinar, arrugar y alisar el último billete de cien pesos que me quedaba, hacer comparaciones entre Elena Sala y la Queca, muertas, imaginar biografías para los titulares de las esquelas de defunción 
que encontraba en los diarios, descubrir que el amor debe desembocar rápidamente en la muerte. Periódicos viejos y tostados se estiraban en la ventana de la fonda y me defendían del sol; yo podía desgarrarlos y mirar hacia Santa María, volver a pensar que todos los hombres que la habitaban habían nacido de mí y que era capaz de hacerles concebir el amor como un absoluto, reconocerse a sí mismos en el acto de amor y aceptar para siempre esta imagen, transformarla en un cauce por el que habría de correr el tiempo y su carga, desde la definitiva revelación hasta la muerte; que, en último caso, era capaz de proporcionar a cada uno de ellos una agonía lúcida y sin dolor para que comprendieran el sentido de lo que habían vivido... Todos eran míos, nacidos de mí, y les tuve lástima y amor ${ }^{17}$.

Esas gentes malditas que habitan Santa María en la ansiedad y el desasosiego de saberse desamparadas, se imprimen para siempre en nuestra imaginación desde esta novela. Cuentos y novelas remiten una y otra vez a situaciones y personajes que conocimos leyendo La vida breve. Onetti construye su obra novelística sobre la autorreferencialidad y la intertextualidad de ésta. La piedra fundacional de la ciudad o civilización sanmariana ha sido echada en La vida breve, y Brausen es su fundador y prócer; su figura regirá en forma de estatua desde la plaza principal, y estará acuñada en las monedas bráusenes. Santa María se despliega como universo autosuficiente muchos años antes de que existiesen la Comala de Juan Rulfo (Pedro Páramo, 1956) o el Macondo de García Márquez (vislumbrado desde La hojarasca, de 1952 pero desplegado plenamente e imborrable desde Cien años de soledad, 1967), con sus plazas, hoteles y cafés, prolongándose en sus arrabales y la colonia de suizos antes emprendedores, luego especuladores de la miseria general (Dejemos hablar al viento, 1979), caídos finalmente en la ruina, como el resto (Cuando ya no importe, 1993). Los personajes de ese mundo aparecen en $\mathrm{La}$ vida breve a veces apenas insinuados por un gesto o un apellido aparentemente insignificantes: Así el soñador y rebelde poeta adolescente Jorge Malabia (narrador principal y cuestionador de la autoridad de quien cuenta una historia en la novela Una tumba sin nombre, 1959; protagonista de "El álbum"; adulto en el exilio madrileño en "Presencia", un cuento de fines de los setenta), el padre Bergner (un antecedente del padre García de La casa verde de Vargas Llosa) y el gallego Lanza, dueño del periódico

17 Op. cit., p. 271. 
El Liberal (Juntacadáveres, 1964); la madura prostituta María Bonita de tantas narraciones; el comisario de policía Medina (melancólico pintor, terminante protagonista de la primera novela que Onetti pudo concebir desde Madrid: Dejemos hablar al viento, de 1979, en la que Medina borra del mapa la ciudad, incendiándola); y por supuesto Larsen, ese hombre calvo y algo obeso, el idealista con la obsesión artística por excelencia: La de construir en la costa de Santa María el prostíbulo perfecto, empresa en la que fracasará como en todas las demás que se proponga (Juntacadáveres, 1964; El astillero, 1961; Carroña/Junta comido por gusanos, regentando un hotel de citas en Dejemos hablar al viento, 1979); allí aparecen, también, otros apellidos sanmarianos fundamentales -como el del empresario Jeremías Petrus-, los cuales se ramificarán como las vidas hacia la muerte y cobrarán su sentido pleno recién cada vez que el autor llame a los distintos personajes y los haga actuar para nosotros lectores, a lo largo de historias personales de decadencia y ruina, en cuarenta años de escritura de Onetti.

\section{Cuatro}

En 1993, pocos meses antes de morir, Onetti dio a conocer la que sería su última narración, de difícil determinación genérica: Cuando ya no importe $^{18}$. "Apuntes garrapateados", diario que escribe el protagonista Juan Carr desde una misión para la cual le pagan, y que consiste en consentir un contrabando peligroso e incierto, mientras simula dirigir la construcción de una represa, prolijo memorándum de los largos diálogos mantenidos por el narrador principal y el otro, el doctor Díaz Grey; en esta obra Onetti resucita a Santa María de las cenizas a las que la creímos reducida en Dejemos hablar al viento. Es una Santa María sumida también en la decrepitud, desacralizada impiadosamente por su creador, y además más tropical y tercermundista. En esta obra el creador de Santa María se despide y confiesa para sí el pudor con que nos ha mostrado a todos sus personajes:

Ahora, definitivamente, para siempre en Montevideo, persisto en redactar apuntes porque absurdamente siento que debo hacerlo como cumpliendo un juramento sagrado que nunca hice pero que lo siento

18 Onetti, J.C. Cuando ya no importe. Buenos Aires: Alfaguara, 1993. 
impuesto... Me escondo porque aquí hay personas, sobre todo mujeres, cuyas caras y renuncias me niego a conocer después de tantos años. Por iguales motivos me disgusta mostrarles mi cara de hoy, permitir que sospechen o adivinen algo de mis pasadas, pequeñas infamias ${ }^{19}$.

También en este texto imagina un tiempo inclemente, como el de su astillero, para quedarse definitivamente en su ciudad primera, a la que regresa en sueños, vale decir, en escritura:

Hay en esta ciudad un cementerio marino más hermoso que el poema $^{20}$. Y hay o había o hubo allí, entre verdores y el agua, una tumba en cuya lápida se grabó el apellido de mi familia. Luego, en algún día repugnante del mes de agosto, lluvia, frío y viento, iré a ocuparlo con no sé qué vecinos. La losa no protege totalmente de la lluvia y, además, como ya fue escrito, lloverá siempre ${ }^{21}$.

Es cierto que toda literatura trata del amor y la soledad. Cada narración de Onetti es también una historia de amor, a menudo incestuoso, y de su contracara, el desamor. Pero el tema básico es la búsqueda de sentido a la vida, una empresa de antemano condenada al fracaso, pero ante la cual sus personajes no se entregan, como no se entrega el autor, quien sabe que lo único irreversible no se cambia con la escritura. Hay, pese a ello, un triunfo, el del verdadero arte. Hay un misterio casi revelado en su prosa, dimensiones vitales, sentimientos o el nombre que les damos, que después de leer a Onetti no volverán a tener el mismo significado, porque en la lectura de este autor se han cargado de una significación milagrosamente nueva: piedad, ternura, odio, vejez, respeto, amor.

19 Op. cit., p. 204.

20 Op. cit., 205. Alude al poema “Le cimetiére marin” de Paul Valéry (m. 1945).

21 Op. cit., p. 205. Lloverá siempre (1953) se titula la única novela del escritor uruguayo Carlos Denis Molina (m. 1983), amigo de Onetti. 
